\title{
The Corrosion Performance of Galvanized Steel in Closed Rusty Seawater
}

\author{
Shuan Liu, ${ }^{1,2}$ Huyuan Sun, ${ }^{1}$ Ning Zhang, ${ }^{1,2}$ and Lijuan Sun ${ }^{1}$ \\ ${ }^{1}$ Key Laboratory of Marine Environmental Corrosion and Bio-Fouling, Institute of Oceanology, \\ Chinese Academy of Sciences, Qingdao 266071, China \\ ${ }^{2}$ Graduate University of Chinese Academy of Sciences, Beijing 100049, China
}

Correspondence should be addressed to Huyuan Sun; sun@qdio.ac.cn

Received 19 July 2013; Accepted 21 October 2013

Academic Editor: W. Ke

Copyright (C) 2013 Shuan Liu et al. This is an open access article distributed under the Creative Commons Attribution License, which permits unrestricted use, distribution, and reproduction in any medium, provided the original work is properly cited.

\begin{abstract}
The corrosion performance of galvanized steel in closed rusty seawater (CRS) was investigated using weight loss, Tafel polarization curve, and electrochemical impedance spectroscopy. Scanning electron microscopy (SEM) and energy dispersive spectroscopy (EDS) were carried out for morphological and chemical characterization of the rust layer absorbed on the zinc coating. Effects of temperature and hydrostatic pressure on corrosion resistance of galvanized steel were studied. Results indicated that rust layer could induce pitting corrosion on the zinc coating under the $\mathrm{Cl}^{-}$erosion; high temperature accelerated the corrosion rate of zinc coating and inhibited the absorption of rust layer; the polarization resistance $\left(R_{p}\right)$ of galvanized steel increased with the increase of hydrostatic pressure in CRS.
\end{abstract}

\section{Introduction}

The PVC encapsulated galvanized steel wire is widely applied in submarine cable project in recent years [1]. PVC is coated on the surface of galvanized steel by thermal compression. This PVC coating can prevent the penetration of seawater and air and then inhibit the corrosion of galvanized steel. However, the failure of PVC will result in the penetration of seawater with immersion time, and the initial rust layer produced on the surface of the galvanized steel cannot fall off because the coating of PVC. Thus, the galvanized steel was always immersed in a closed saturated rusty seawater environment (Figure 1).

It is acknowledged that when galvanized steel is exposed to marine environment, the main corrosion products $\left(\mathrm{Zn}_{5}(\mathrm{OH})_{2} \mathrm{Cl}_{8}\right)$ have been found in longer exposure periods $[2,3]$. When the galvanized steel is coated by PVC and used as cables in seawater, the corrosion performance of galvanized steel under this closed rusty seawater (CRS) is primary in the process of metallic corrosion $[4,5]$. It is expected that the corrosion performance of galvanized steel may be different since the rust layer affects corrosion-related processes, such as the mass transport of dissolved oxygen $[6,7]$, the stability of the passive film, and the hydration of the dissolved metal ions [8-10]. There are few reports regarding the corrosion behavior of galvanized steel under closed rusty seawater environment.

In our previous works, it had been demonstrated that $\mathrm{Cl}^{-}$concentration and $\mathrm{pH}$ have very important effects on corrosion behavior of galvanized steel under simulated rust layer solution [11, 12]. In the present work, the saturated $\mathrm{Zn}_{5} \mathrm{Cl}_{2}(\mathrm{OH})_{8}$ seawater is used to simulate the closed rusty seawater (CRS) environment. The corrosion performance of galvanized steel in CRS was investigated by means of conventional electrochemical techniques, including polarization curve and electrochemical impedance spectroscopy (EIS). Effects of temperature and hydrostatic pressure on corrosion resistance of galvanized steel were studied in detail.

\section{Experimental}

2.1. Experimental Design. The electrochemical tests were carried out in a closed environment and the experimental apparatus was depicted in Figure 2. An important issue is that the cell remains well-sealed. To meet this requirement, 


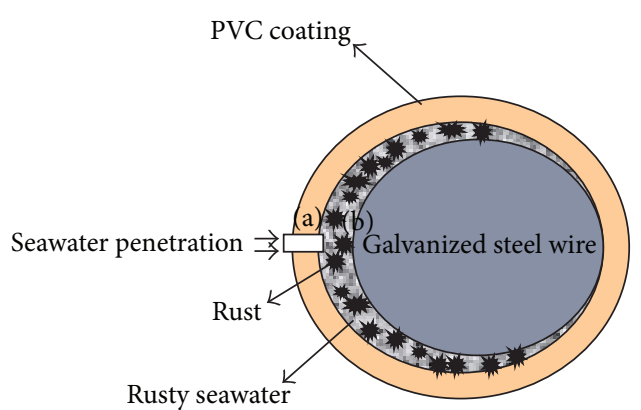

FIGURE 1: Schematic diagram of galvanized steels coated by PVC: (a) the failure zone of the PVC coating, (b) the corroded surface of the galvanized steel.

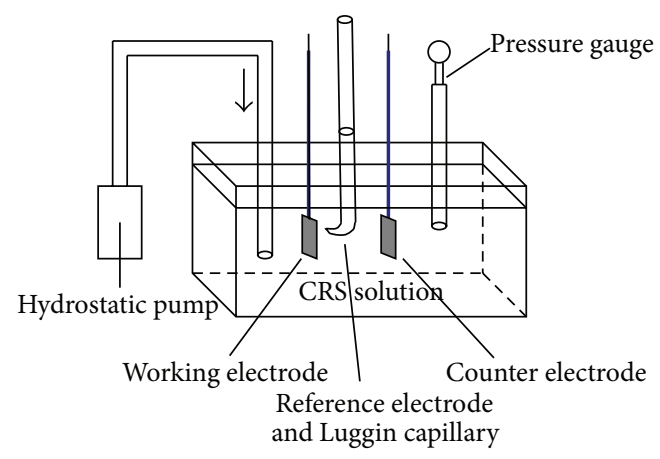

FIGURE 2: Schematic diagram of the electrochemical test cell under different hydrostatic pressures in CRS solution.

the cell was fabricated with high precision and the edge was sealed with epoxy. The working electrode was machined from commercial galvanized steel with a composition of the zinc coating containing (wt $\%) 0.2 \% \mathrm{Mn}, 0.04 \% \mathrm{C}, 0.01 \% \mathrm{P}, 0.008 \%$ $\mathrm{S}, 0.036 \% \mathrm{Ti}$ and the balance zinc. The exposed area of the electrode was $1 \times 1 \mathrm{~cm}^{2}$, the side surface of the specimen was sealed by epoxy, and a copper wire was connected to the backside of each electrode. Before each test, the working surface of the electrode was degreased with ethanol, then cleaned with distilled water, and then dried in air. Counter electrode was a platinum sheet and reference electrode was a saturated calomel electrode (SCE). All potentials in this paper were reported in the SCE scale.

2.2. Test Medium. The seawater used in the experiment was taken from Huiquan Bay of Qingdao (east longitude $119^{\circ} 30^{\prime} \sim 121^{\circ} 00^{\prime}$, north latitude $35^{\circ} 35^{\prime} \sim 37^{\circ} 09^{\prime}$, pH 7.87 7.92, and salinity $30.26 \%$ o $30.38 \%$ ). The closed rusty seawater (CRS) was prepared by adding $\mathrm{Zn}_{5}(\mathrm{OH})_{2} \mathrm{Cl}_{8}$ to seawater, and more $\mathrm{Zn}_{5}(\mathrm{OH})_{2} \mathrm{Cl}_{8}$ precipitation was added to the test solution to maintain saturation [11]. The experiment was carried out in March 2013 (the ambient temperature was about $293 \mathrm{~K}$ ), and the hydrostatic pressure of the test solution was controlled with a SB-2.5-6 manual hydraulic pump.

2.3. Weight Loss Measurement. According to ISO standards 8407-1991, weight loss tests were conducted in seawater and

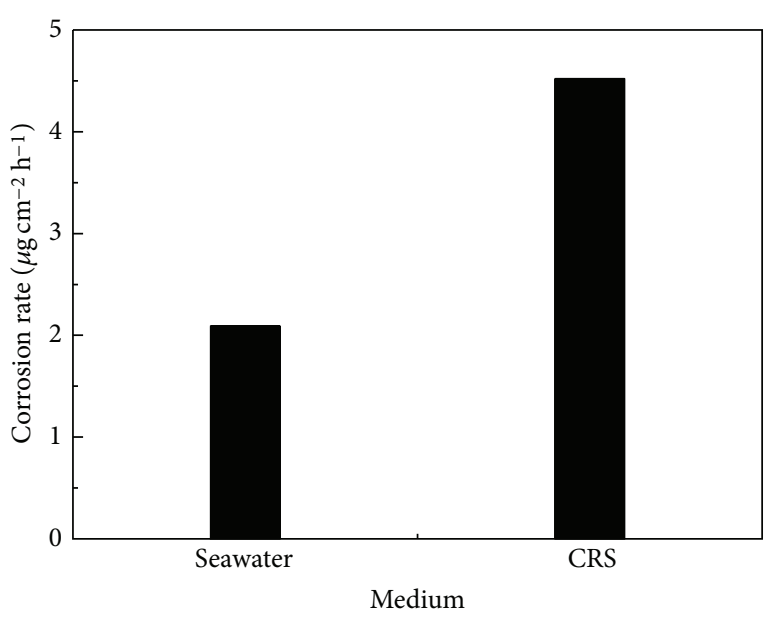

FIgURE 3: Corrosion rate of galvanized steel immersed at $0.1 \mathrm{MPa}$ hydrostatic pressure and $293 \mathrm{~K}$ in seawater and CRS solution after 30 days.

CRS at ambient temperature. The specimens were weighed before the tests. To determine the loss of weight, the specimens were removed after 30 days and the rust layer was scraped off by a surgical blade. The residual rust on specimen was removed by immersion in $\mathrm{NH}_{4} \mathrm{Cl}$ solution $(100 \mathrm{~g} / \mathrm{L})$ at $343 \mathrm{~K}$ for $5 \mathrm{~min}$, washed with abundant distilled water, dried, and then weighed to determine their mass loss.

2.4. Electrochemical Experiments. Tafel polarization curves were acquired using an EG\&G 2273 potentiostat at a scan rate of $0.5 \mathrm{mV} / \mathrm{s}$, and the electrochemical parameters were fitted by CView2 software. For the linear polarization measurement, a sweep range of -10 to $+10 \mathrm{mV}$ versus OCP at a sweep rate of $0.166 \mathrm{mV} / \mathrm{s}$ was used, and the polarization resistance $\left(R_{p}\right)$ was determined from the slope of the potential $(E)$ versus current $(i)$ curve in the vicinity of the corrosion potential [13]. The EIS measurements were performed at OCP with a $10 \mathrm{mV}$ AC perturbation at the frequency from $100 \mathrm{kHz}$ to $10 \mathrm{mHz}$, with 5 points per decade. The frequency sweep of the EIS was always taken from high to low. ZView2 software was used to analyze the EIS data with equivalent circuits. Both the polarization curves and EIS measurements were repeated three times for the reproducibility.

2.5. Surface Characterization. The microstructure of the rust layer absorbed on the surface of electrode was observed and recorded by using a KYKY-2800B SEM, and the field emission energy was $10 \mathrm{keV}$. The chemical composition of the corrosion products was determined using a GENESIS 4000 energy dispersive spectroscopy (EDS) attached to the SEM.

\section{Results and Discussion}

3.1. Weight Loss Measure. Figure 3 showed the corrosion rate of specimens immersed in seawater and CRS after 30 days at ambient temperature. The corrosion rate of galvanized steel in CRS $\left(4.52 \mu \mathrm{g} / \mathrm{cm}^{2} \mathrm{~h}\right)$ was 2.16 times faster than that 

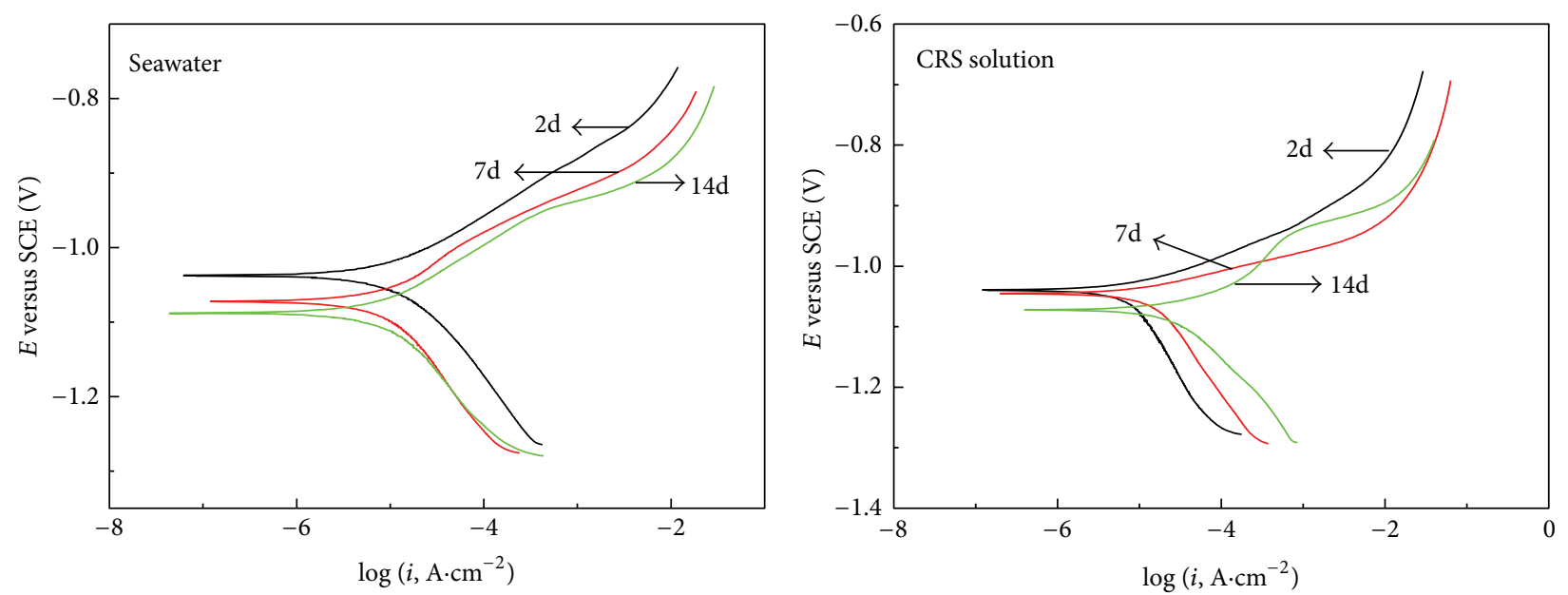

FIGURE 4: Tafel polarization curves of galvanized steel immersed at $0.1 \mathrm{MPa}$ hydrostatic pressure and $293 \mathrm{~K}$ in seawater and CRS solution after different immersion times.

TABLE 1: Electrochemical parameters of galvanized steel calculated from polarization curve at $0.1 \mathrm{MPa}$ and $293 \mathrm{~K}$ in seawater and CRS solution.

\begin{tabular}{lcccc}
\hline & $\begin{array}{c}E_{\text {corr }} \\
V \text { versus SCE }\end{array}$ & $\begin{array}{c}i_{\text {corr }} \\
\mu \mathrm{A} \mathrm{cm}^{-2}\end{array}$ & $\begin{array}{c}\beta_{a} \\
\mathrm{mV} / \mathrm{dec}\end{array}$ & $\begin{array}{c}\beta_{c} \\
\mathrm{mV} / \mathrm{dec}\end{array}$ \\
\hline Sea-2d & -1.036 & 15.17 & 158.6 & 220.3 \\
Sea-7d & -1.073 & 22.91 & 132.53 & 234.2 \\
Sea-14d & -1.089 & 37.12 & 148.3 & 235.5 \\
CRS-2d & -1.041 & 18.58 & 57.7 & 211.2 \\
CRS-7d & -1.043 & 25.56 & 41.6 & 186.3 \\
CRS-14d & -1.075 & 58.34 & 35.2 & 196.4 \\
\hline
\end{tabular}

in seawater $\left(2.09 \mu \mathrm{g} / \mathrm{cm}^{2} \mathrm{~h}\right)$, suggesting that corrosion of galvanized steel in CRS solution proceeded much faster than that in seawater.

3.2. Corrosion Behavior of Galvanized Steel in Seawater and CRS. Figure 4 showed the Tafel polarization curves of galvanized steel in seawater and CRS solution under different immersion times, respectively. The corrosion parameters, fitted from the Tafel region of Figure 4 using Powersuite software, were listed in Table 1 . The corrosion potential $\left(E_{\text {corr }}\right)$ shifted to the negative direction with immersion time in seawater and CRS, indicating the further degradation of the zinc coating. In CRS solution, the evolution of corrosion current density $\left(i_{\text {corr }}\right)$ was similar to that of seawater; however, both of the $\beta_{a}$ and $\beta_{c}$ values were smaller and the $i_{\text {corr }}$ was larger than that in seawater, indicating that the rust layer absorbed on the electrode surface accelerated the corrosion rate of galvanized steel [14]. These results were consistent with the weight loss measurement completely.

3.2.1. The Effect of Temperature on Corrosion Behavior in CRS Solution. The EIS evolution of galvanized steel after exposure to CRS under different temperature was shown in Figure 5.
To obtain the electrochemical parameters, two equivalent circuits shown in Figures 6(a) and 6(b) were used for fitting EIS data of galvanized steel in CRS under different temperature, respectively. The corresponding electrochemical parameters were listed in Table 2. From the Bode plots of Figure 5, there are two time constants occurred during the whole immersion times $[15,16]$. The capacitive semicircle at high frequency is associated with the rust layer absorbed on the electrode surface, and the capacitive semicircle at the medium-low frequency is attributed to the double layer capacitance and charge-transfer resistance $[17,18]$. When the temperature was $293 \mathrm{~K}$, a Warburg impedance corresponding to oxygen diffusion appeared at the low frequency. Figure 6(a) was used to fit the EIS data only displaying two capacitive loops, whereas the second one (Figure 6(b)) was used to fit the EIS data displaying a Warburg impedance.

In the equivalent circuit, the capacitance is replaced by the constant phase angle element $Q$, because a dispersion effect can be caused by microscopic roughness in the CRS solution [19]. $Q$ is expressed as $\omega^{-n} / Y_{0} \cdot(\cos n \pi / 2+j \sin n \pi / 2)$, where $Y_{0}$ and $n$ are the constant and exponent, respectively, $\omega$ is the angular frequency in $\operatorname{rads}^{-1}(\omega=2 \pi f)$, and $j^{2}=-1$ is an imaginary number [20]. $R_{s}$ is the solution resistance, $Q_{1}$ and $R_{f}$ are the capacitance and resistance of rust layer, respectively, $Q_{2}$ is the double layer capacitance, and $R_{\mathrm{ct}}$ is the charge transfer resistance; $W$ represents the oxygen diffusion impedance [21].

The diameter of the semicircle of impedance spectrum increased with immersion time at different temperatures and the corresponding EIS fitting results $\left(R_{f}\right.$ and $\left.R_{\mathrm{ct}}\right)$ of galvanized steel were shown in Figure 7. The $R_{f}$ increased with time at low temperature (273 293 K) suggesting the thickness of rust layer absorbed on the electrode was thickened. However, The $R_{f}$ decreased with time at high temperature $(313 \sim 333 \mathrm{~K})$. Obviously, the $R_{f}$ values at high temperature $(313 \sim 333 \mathrm{~K})$ were much lower than those at low temperature (273 293 K), indicating that the high temperature inhibited 

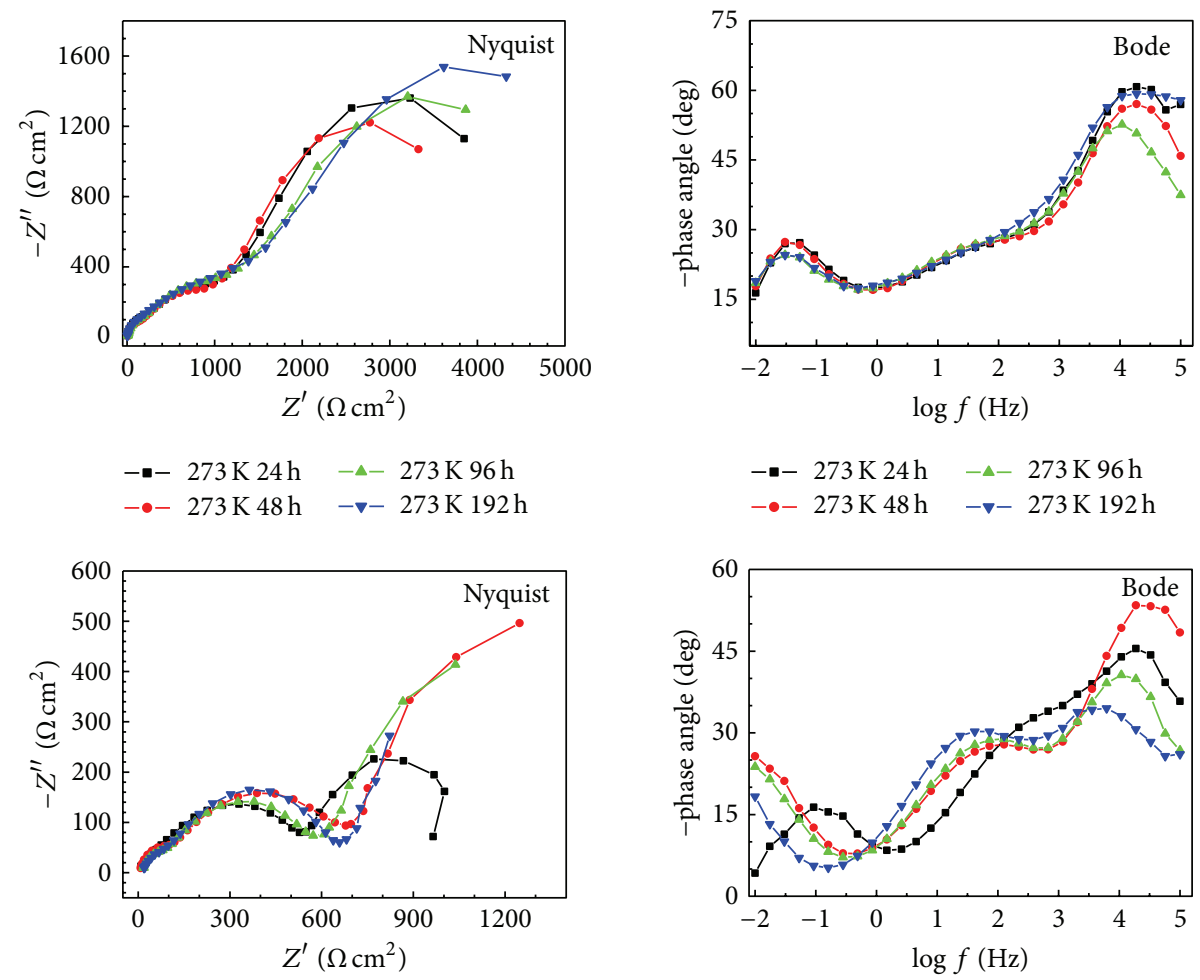

$--293 \mathrm{~K} 24 \mathrm{~h} \quad-\Delta-293 \mathrm{~K} 96 \mathrm{~h}$

$-\bullet-293 \mathrm{~K} 24 \mathrm{~h} \quad-\Delta-293 \mathrm{~K} 96 \mathrm{~h}$

$-\bullet-293 \mathrm{~K} 48 \mathrm{~h} \quad-\nabla-293 \mathrm{~K} 192 \mathrm{~h}$
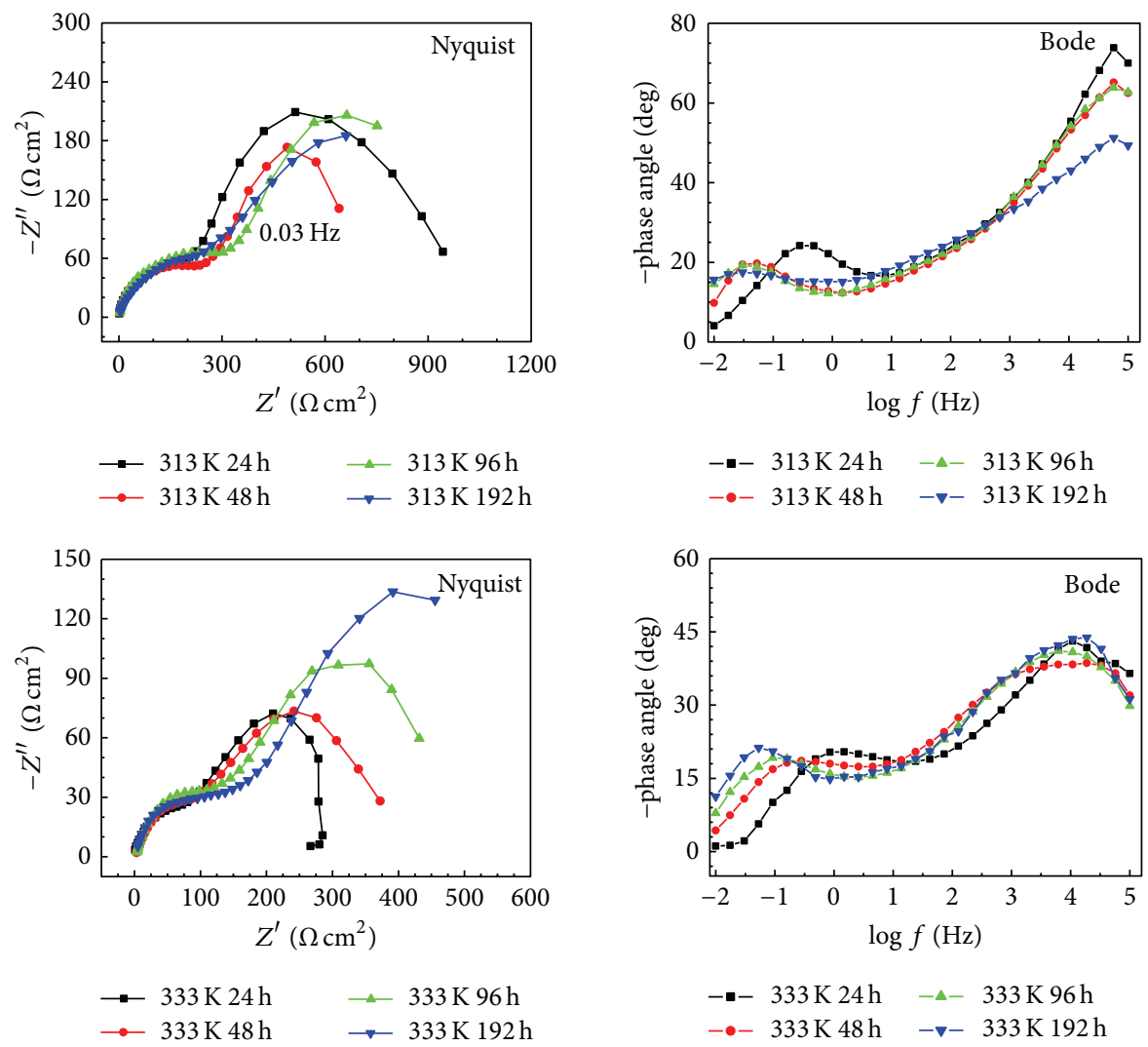

FIGURE 5: EIS curves of galvanized steel in CRS solution at $0.1 \mathrm{MPa}$ under different temperatures. 


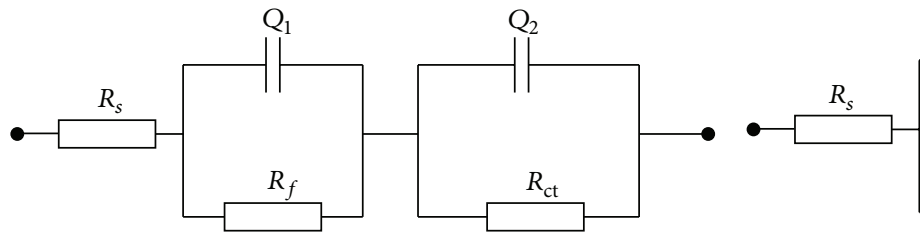

(a)
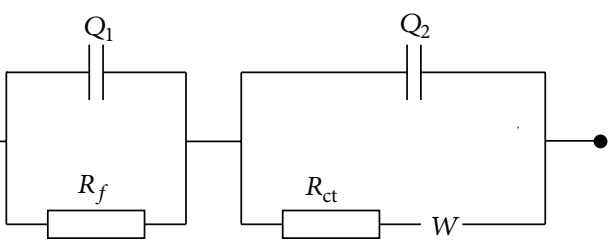

(b)

FIgURE 6: Two equivalent circuit models used to fit the experiment impedance data of galvanized steel in SRL solution.

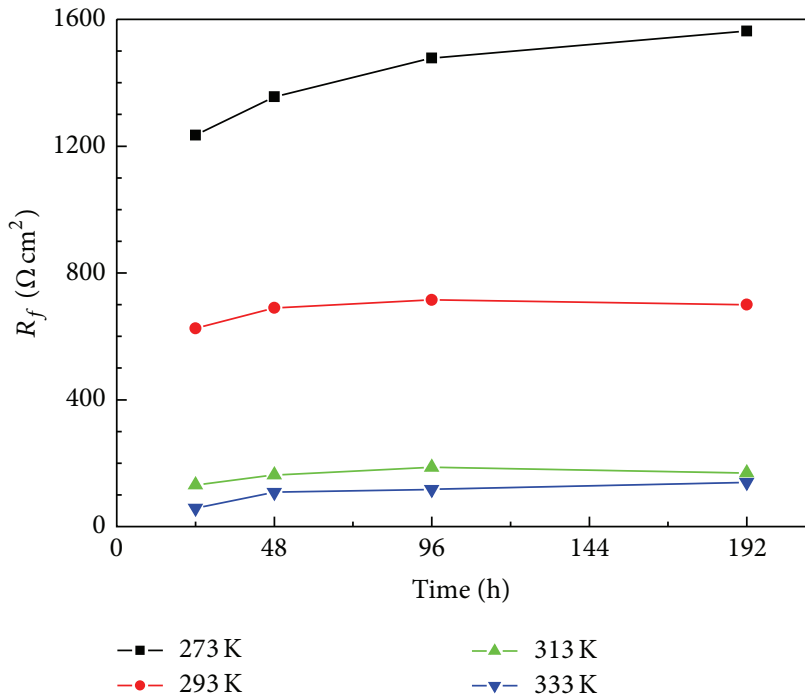

(a)

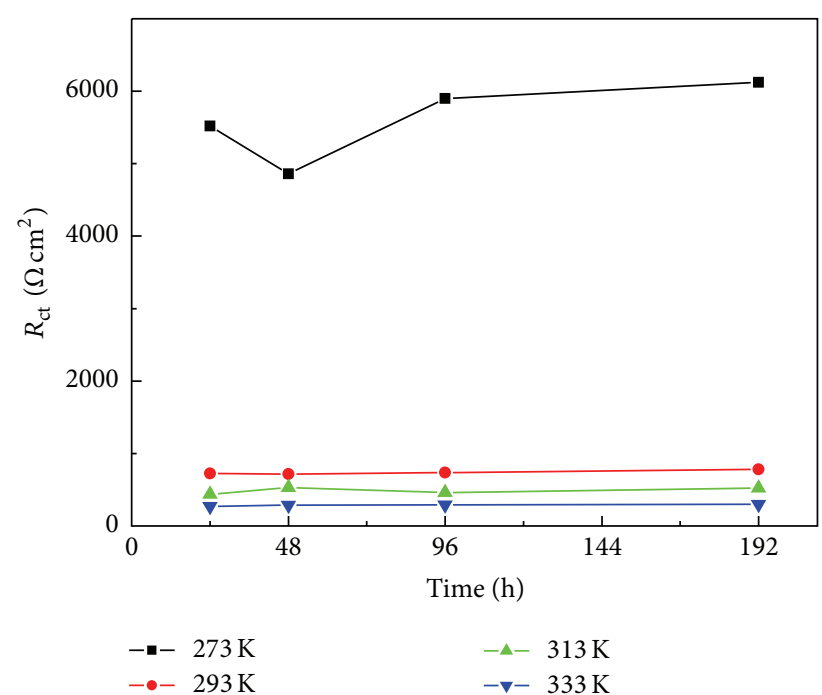

(b)

FIGURE 7: Changes of $R_{f}(\mathrm{a})$ and $R_{\mathrm{ct}}(\mathrm{b})$ in CRS solution at $0.1 \mathrm{MPa}$ under different temperatures.

TABLE 2: EIS fitting parameters of galvanized steel after various immersion times in CRL solution at 0.1 MPa under different temperatures $(273,293,313$, and $333 \mathrm{~K})$.

\begin{tabular}{|c|c|c|c|c|c|c|c|c|c|}
\hline & $\begin{array}{l}\text { Time } \\
\text { hours }\end{array}$ & $\begin{array}{c}R_{s} \\
\Omega \mathrm{cm}^{2}\end{array}$ & $\mu \mathrm{F} \mathrm{cm}^{-2} \mathrm{~Hz}^{1-n_{1}}$ & $n_{1}$ & $\begin{array}{c}R_{f} \\
\Omega \mathrm{cm}^{2}\end{array}$ & $\mu \mathrm{F} \mathrm{cm}^{-2} \mathrm{~Hz}^{1-n_{2}}$ & $n_{2}$ & $\begin{array}{c}R_{\mathrm{ct}} \\
\Omega \mathrm{cm}^{2}\end{array}$ & $\begin{array}{c}W \\
\Omega \mathrm{cm}^{2}\end{array}$ \\
\hline \multirow{4}{*}{$273 \mathrm{~K}$} & 24 & 0.01 & 7.56 & 0.59 & 1235 & 102.5 & 0.59 & 5523 & - \\
\hline & 48 & 0.01 & 12.23 & 0.74 & 1356 & 241.8 & 0.68 & 4862 & - \\
\hline & 96 & 0.01 & 53.58 & 0.62 & 1478 & 91.5 & 0.58 & 5900 & - \\
\hline & 192 & 0.01 & 89.56 & 0.61 & 1563 & 101.8 & 0.65 & 6123 & - \\
\hline \multirow{4}{*}{$293 \mathrm{~K}$} & 24 & 0.01 & 9.6 & 0.54 & 625.1 & 312.4 & 0.94 & 439.2 & - \\
\hline & 48 & 0.01 & 14.2 & 0.78 & 690.2 & 91.6 & 0.91 & 530.8 & 0.00412 \\
\hline & 96 & 0.01 & 21.2 & 0.95 & 714.5 & 242.8 & 0.61 & 459.9 & 0.00462 \\
\hline & 192 & 0.01 & 140.5 & 0.85 & 700.2 & 135.2 & 0.59 & 521.5 & 0.0189 \\
\hline \multirow{4}{*}{$313 \mathrm{~K}$} & 24 & 0.01 & 130.1 & 0.60 & 131.2 & 25.3 & 0.74 & 725 & - \\
\hline & 48 & 0.01 & 52.3 & 0.59 & 162.6 & 252.7 & 0.59 & 714.4 & - \\
\hline & 96 & 0.01 & 40.9 & 0.63 & 187.2 & 245.3 & 0.62 & 736.5 & - \\
\hline & 192 & 0.01 & 190.5 & 0.52 & 168.9 & 23.5 & 0.68 & 778.3 & - \\
\hline \multirow{4}{*}{$333 \mathrm{~K}$} & 24 & 0.01 & 41.2 & 0.57 & 58.6 & 169.2 & 0.65 & 270.3 & - \\
\hline & 48 & 0.01 & 56.5 & 0.61 & 108.5 & 452.1 & 0.71 & 286.4 & - \\
\hline & 96 & 0.01 & 94.5 & 0.59 & 117.3 & 475.5 & 0.62 & 290.5 & - \\
\hline & 192 & 0.01 & 156.4 & 0.88 & 139.5 & 412.7 & 0.58 & 298.6 & - \\
\hline
\end{tabular}



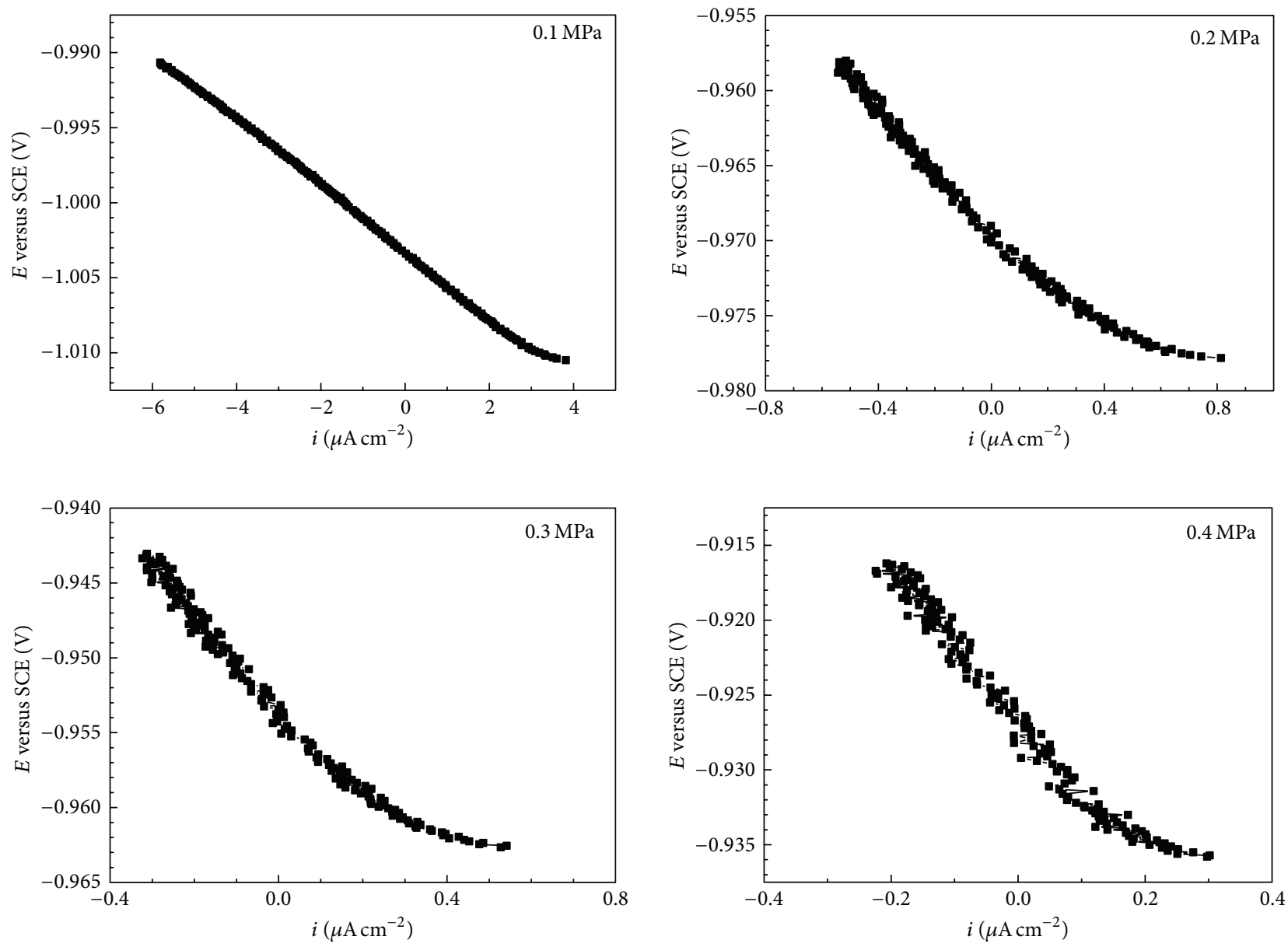

FIGURE 8: Linear polarization curves of galvanized steel under different hydrostatic pressure in CRS solution at $293 \mathrm{~K}$ after 2 days.

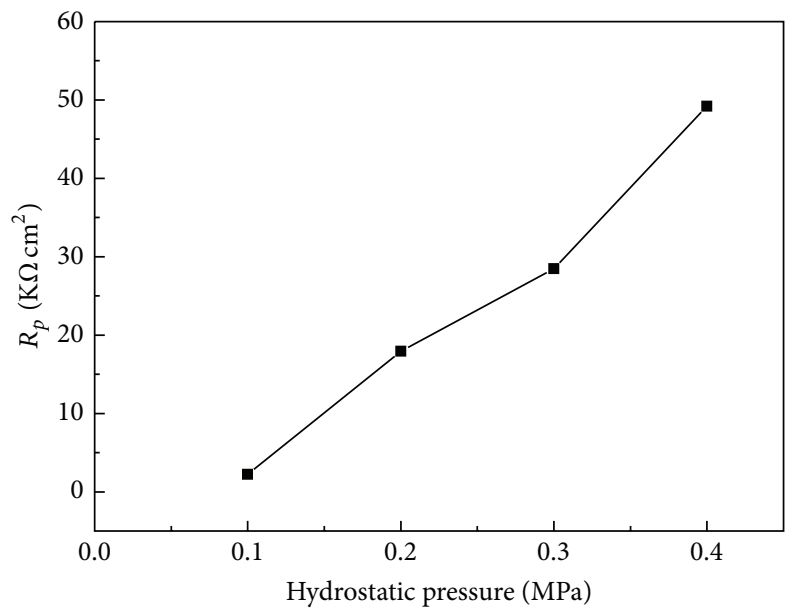

FIGURE 9: Evolution of $R_{p}$ estimated by linear polarization curves under different hydrostatic pressure in CRS solution at $293 \mathrm{~K}$ after 2 days.

the adsorption of the rust layer. When the temperature was constant, the $R_{\mathrm{ct}}$ almost kept invariant. The $R_{\mathrm{ct}}$ values at $273 \mathrm{~K}$ were much larger than those at $293 \mathrm{~K}, 313 \mathrm{~K}$, and $333 \mathrm{~K}$ in CRS, indicating that the high temperature accelerated the corrosion rate of galvanized steel in CRS [22].
3.2.2. The Effect of Hydrostatic Pressure on Corrosion Behavior in CRS Solution. The linear polarization curves of galvanized steel under different hydrostatic pressure in CRS were shown in Figure $8 . E_{\text {corr }}$ shifted from a negative value to a positive one with the increase of hydrostatic pressure and the linear 


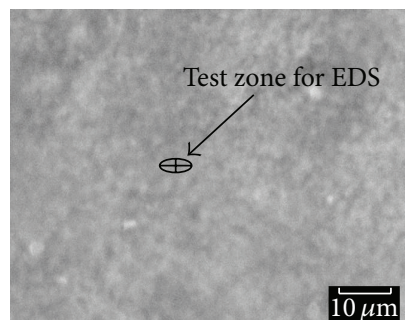

(a)

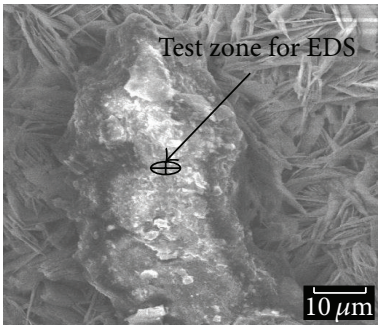

(c)

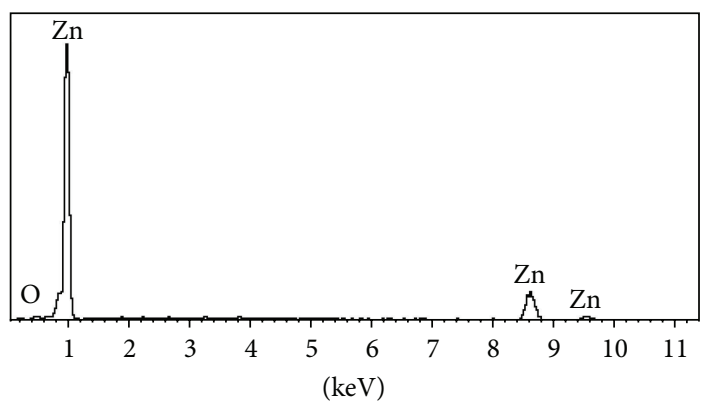

(b)

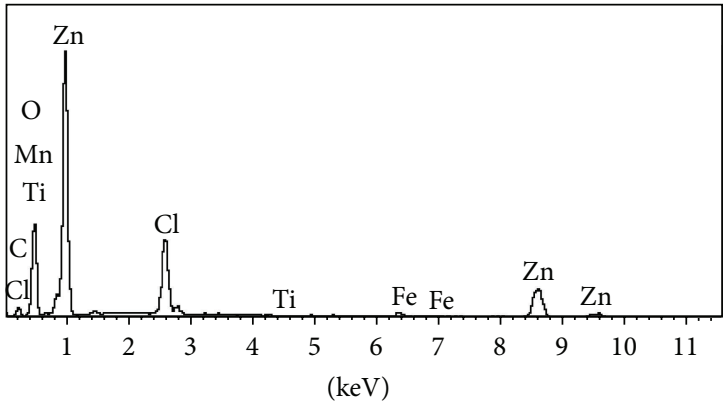

(d)

FIGURE 10: SEM and EDS analysis of galvanized steel immersed in CRS solution in 0.1 MPa. (a) SEM image of galvanized steel before immersion; (b) EDS result of (a); (c) SEM image of galvanized steel immersed in CRS solution at 0.1 MPa hydrostatic pressures after 14 days; (d) EDS result of (c) in the pitting area.

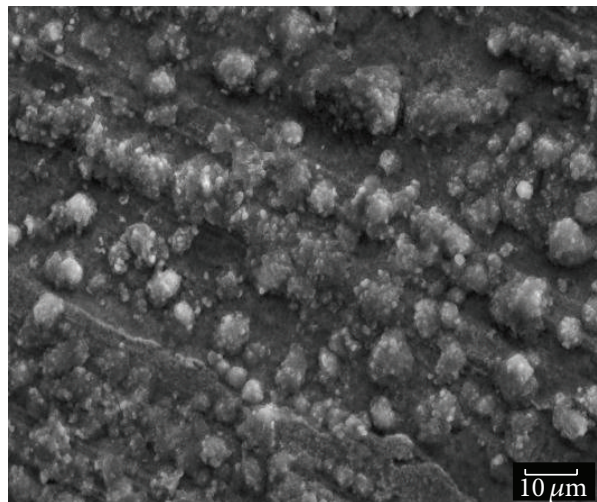

(a)

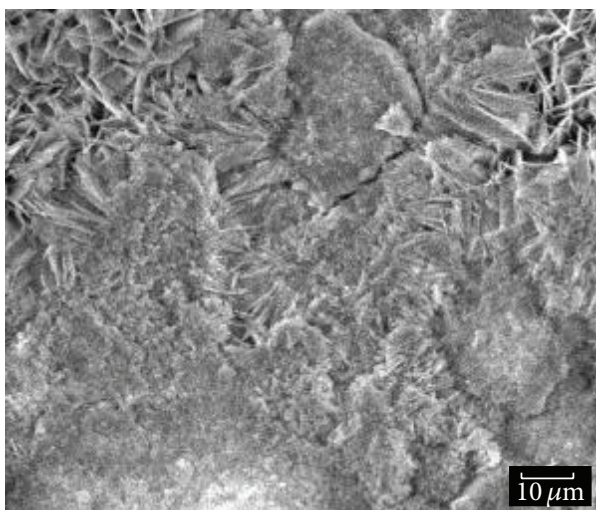

(c)

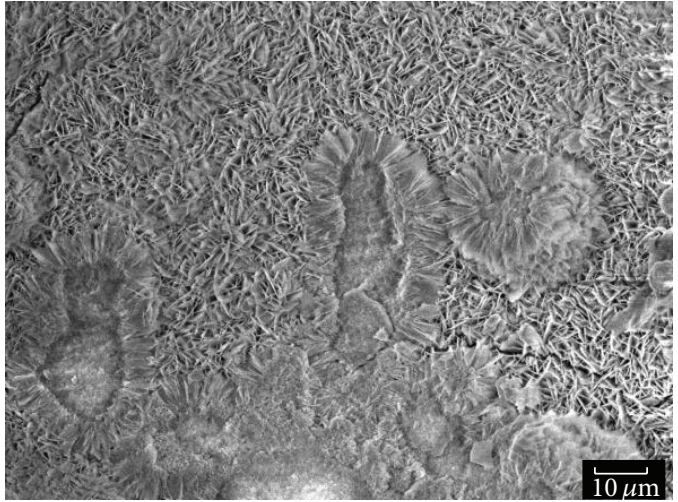

(b)

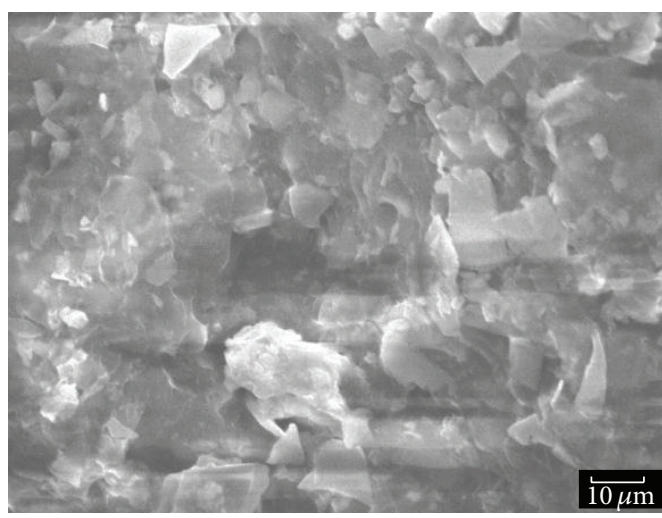

(d)

FIGURE 11: SEM images of galvanized steel immersed in CRS solution under different temperatures in $0.1 \mathrm{MPa}$ after 14 days, (a) $273 \mathrm{~K}$; (b) $293 \mathrm{~K}$; (c) $313 \mathrm{~K}$; (d) $333 \mathrm{~K}$ 


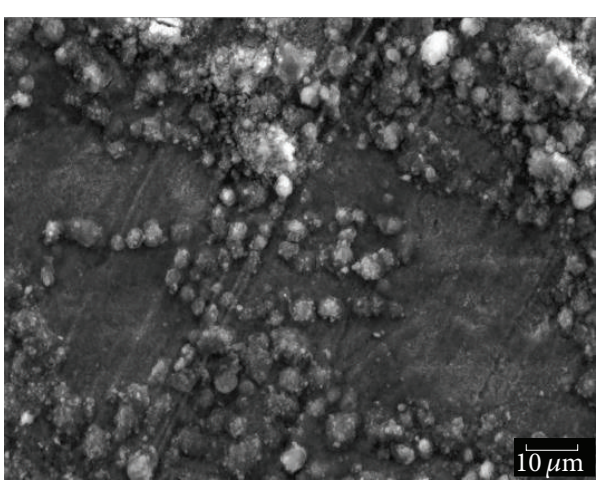

(a)

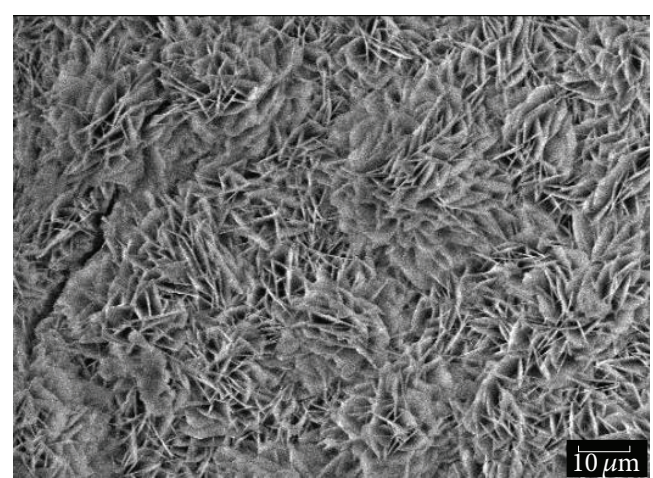

(b)

FIGURE 12: SEM images of galvanized steel immersed in CRS solution under different hydrostatic pressure at $293 \mathrm{~K}$ after 2 days, (a) $0.1 \mathrm{MPa}$; (b) $0.4 \mathrm{MPa}$.

polarization curves became nonlinear gradually. These were due to the reason that under high hydrostatic pressure, the rust layer was tightly absorbed on the surface of galvanized steel (Figure 12). Thus, the fitted zone was chosen in the linear region (from -5 to $+5 \mathrm{mV}$ versus $E_{\text {corr }}$ ), and Figure 9 showed the variations of $R_{p}$ as a function of different hydrostatic pressure. It was observed that the $R_{p}$ increased from 2.23 to $49.18 \mathrm{~K} \Omega \mathrm{cm}^{2}$ with the increase of hydrostatic pressure from 0.1 to $0.4 \mathrm{Mpa}$, indicating that the corrosion resistance of galvanized steel improved with the increase of hydrostatic pressure in CRS.

3.3. Surface Analysis. SEM and EDS were employed to investigate the corrosion behavior of galvanized steel under CRS at different temperatures. Figure 10 showed the SEM and EDS results of specimen before immersion and after 14 days immersion in CRS, respectively. Evidently, the zinc coating was smooth, compact, and completely covered on the specimen surface; no corrosion was found before immersion (Figure 9(a)). $\mathrm{Zn}$ and $\mathrm{O}$ elements were observed before immersion. When the specimen is immersed in CRS after 14 days, needle-like rust layer was absorbed on the electrode surface and the zinc coating was damaged under the erosion of $\mathrm{Cl}^{-} . \mathrm{Zn}, \mathrm{Fe}, \mathrm{Cl}, \mathrm{Ti}, \mathrm{C}$, and $\mathrm{O}$ elements were observed in the pitting zone. Figures 11 and 12 showed the SEM images of galvanized steel under different temperatures $(273,293,313$, and $333 \mathrm{~K}$ ) after 14 days and different hydrostatic pressures (0.1 and $0.4 \mathrm{MPa}$ ) after 2 days in CRS solution, respectively. Loose rust layer was absorbed on the zinc coating at $273 \mathrm{~K}$; however, pitting corrosion occurred on the surface of specimen at $293 \mathrm{~K}$; the zinc coating was damaged seriously at $313 \mathrm{~K}$ and $333 \mathrm{~K}$. When the hydrostatic pressure was $0.1 \mathrm{MPa}$, some spherical rust layer was absorbed on the surface. The rust layer was turned into needle-like shape and absorbed adherently and compactly when the hydrostatic pressure was $0.4 \mathrm{MPa}$. The SEM results indicated that the corrosion of galvanized steel was accelerated with temperature but inhibited under high hydrostatic pressure in CRS solution.

\section{Conclusion}

(1) In closed rusty seawater (CRS) solution, the rust layer absorbed on the surface of galvanized steel accelerated the corrosion rate of zinc coating. Pitting corrosion occurred on the surface of galvanized steel; zinc coating was damaged by the erosion of $\mathrm{Cl}^{-}$.

(2) The corrosion rate of galvanized steel increased with temperature because high temperature inhibited the absorption of rust layer and reduced the chargetransfer resistance in CRS solution.

(3) The polarization resistance of galvanized steel increased with the increase of hydrostatic pressure in CRS solution.

\section{Conflict of Interests}

The authors declare that there is no conflict of interests regarding the publication of this paper.

\section{Acknowledgment}

The authors wish to acknowledge the financial support of the National Science Foundation of China (no. 41076046).

\section{References}

[1] H. Sun, B. Zang, S. Liu, L. Sun, and H. Fan, "Effects of $\mathrm{Zn}(\mathrm{OH})_{2}$ on corrosion behavior of hot dipped $\mathrm{Zn}$ coating in freshwater," Advanced Materials Research, vol. 399-401, pp. 152-155, 2012.

[2] I. Odnevall and M. Westdahl, "The formation of $\mathrm{Zn}_{4} \mathrm{Cl}_{2}$. $(\mathrm{OH})_{4} \mathrm{SO}_{4} \cdot 5 \mathrm{H}_{2} \mathrm{O}$ in an urban and andustrial atmosphere," Corrosion Science, vol. 36, no. 9, pp. 1551-1559, 1994.

[3] Y. Li, "Formation of nano-crystalline corrosion products on $\mathrm{Zn}$ $\mathrm{Al}$ alloy coating exposed to seawater," Corrosion Science, vol. 43, no. 9, pp. 1793-1800, 2001.

[4] X. G. Zhang, Corrosion and Electrochemistry of Zinc, Plenum Press, New York, NY, USA, 1996. 
[5] T. E. Graedel, "Corrosion mechanisms for aluminum exposed to the atmosphere," Journal of the Electrochemical Society, vol. 136, no. 4, pp. 204-212, 1989.

[6] J. Duan, S. Wu, X. Zhang, G. Huang, M. Du, and B. Hou, "Corrosion of carbon steel influenced by anaerobic biofilm in natural seawater," Electrochimica Acta, vol. 54, no. 1, pp. 22-28, 2008.

[7] L. Bousselmi, C. Fiaud, B. Tribollet, and E. Triki, "The characterisation of the coated layer at the interface carbon steel-natural salt water by impedance spectroscopy," Corrosion Science, vol. 39, no. 9, pp. 1711-1724, 1997.

[8] C. Cachet, F. Ganne, G. Maurin, J. Petitjean, V. Vivier, and R. Wiart, "EIS investigation of zinc dissolution in aerated sulfate medium-part I: bulk zinc," Electrochimica Acta, vol. 47, no. 3, pp. 509-518, 2001.

[9] C. Cachet, F. Ganne, S. Joiret et al., "EIS investigation of zinc dissolution in aerated sulphate medium-part II: zinc coatings," Electrochimica Acta, vol. 47, no. 21, pp. 3409-3422, 2002.

[10] T. Tsuru, "Various electrochemical approaches for corrosion engineering," Corrosion Engineering, vol. 59, no. 11, pp. 404-409, 2010.

[11] S. Liu, H. Y. Sun, L. J. Sun, and H. J. Fan, "Effects of pH and $\mathrm{Cl}^{-}$concentration on corrosion behavior of the galvanized steel in simulated rust layer solution," Corrosion Science, vol. 65, pp. 520-527, 2012.

[12] H. Y. Sun, S. Liu, and L. J. Sun, "A comparative study on the corrosion of galvanized steel under simulated rust layer solution with and without $3.5 \mathrm{wt} \% \mathrm{NaCl}$," International Journal of Electrochemical Science, vol. 8, pp. 3494-3509, 2013.

[13] Y. Zou, J. Wang, and Y. Y. Zheng, "Electrochemical techniques for determining corrosion rate of rusted steel in seawater," Corrosion Science, vol. 53, no. 1, pp. 208-216, 2011.

[14] H. Huang, X. Guo, G. Zhang, and Z. Dong, "The effects of temperature and electric field on atmospheric corrosion behaviour of PCB-Cu under absorbed thin electrolyte layer," Corrosion Science, vol. 53, no. 5, pp. 1700-1707, 2011.

[15] S. Liu, Y. Gu, S. L. Wang et al., "Degradation of organic pollutants by a $\mathrm{Co}_{3} \mathrm{O}_{4}$-graphite composite electrode in an electroFenton-like system," Chinese Science Bulletin, vol. 58, pp. 23402346, 2013.

[16] X. N. Liao, F. H. Cao, L. Y. Zheng et al., "Corrosion behaviour of copper under chloride-containing thin electrolyte layer," Corrosion Science, vol. 53, no. 10, pp. 3289-3298, 2011.

[17] Y. L. Cheng, Z. Zhang, F. H. Cao et al., "A study of the corrosion of aluminum alloy 2024-T3 under thin electrolyte layers," Corrosion Science, vol. 46, no. 7, pp. 1649-1667, 2004.

[18] S. Liu, X. R. Zhao, H. Y. Sun, R. P. Li, Y. F. Fang, and Y. P. Huang, "The degradation of tetracycline in a photo-electroFenton system," Chemical Engineering Journal, vol. 231, pp. 441448, 2013.

[19] A. P. Yadav, H. Katayama, K. Noda, H. Masuda, A. Nishikata, and T. Tsuru, "Surface potential distribution over a zinc/steel galvanic couple corroding under thin layer of electrolyte," Electrochimica Acta, vol. 52, no. 9, pp. 3121-3129, 2007.

[20] H. L. Huang, Z. H. Dong, Z. Y. Chen, and X. P. Guo, “The effects of $\mathrm{Cl}^{-}$ion concentration and relative humidity on atmospheric corrosion behaviour of PCB-Cu under adsorbed thin electrolyte layer," Corrosion Science, vol. 53, no. 4, pp. 1230-1236, 2011.

[21] W. Li, H. Tian, and B. Hou, "Corrosion performance of epoxy coatings modified by nanoparticulate $\mathrm{SiO}_{2}$," Materials and Corrosion, vol. 63, no. 1, pp. 44-53, 2012.
[22] A. Popova, E. Sokolova, S. Raicheva, and M. Christov, "AC and DC study of the temperature effect on mild steel corrosion in acid media in the presence of benzimidazole derivatives," Corrosion Science, vol. 45, no. 1, pp. 33-58, 2003. 

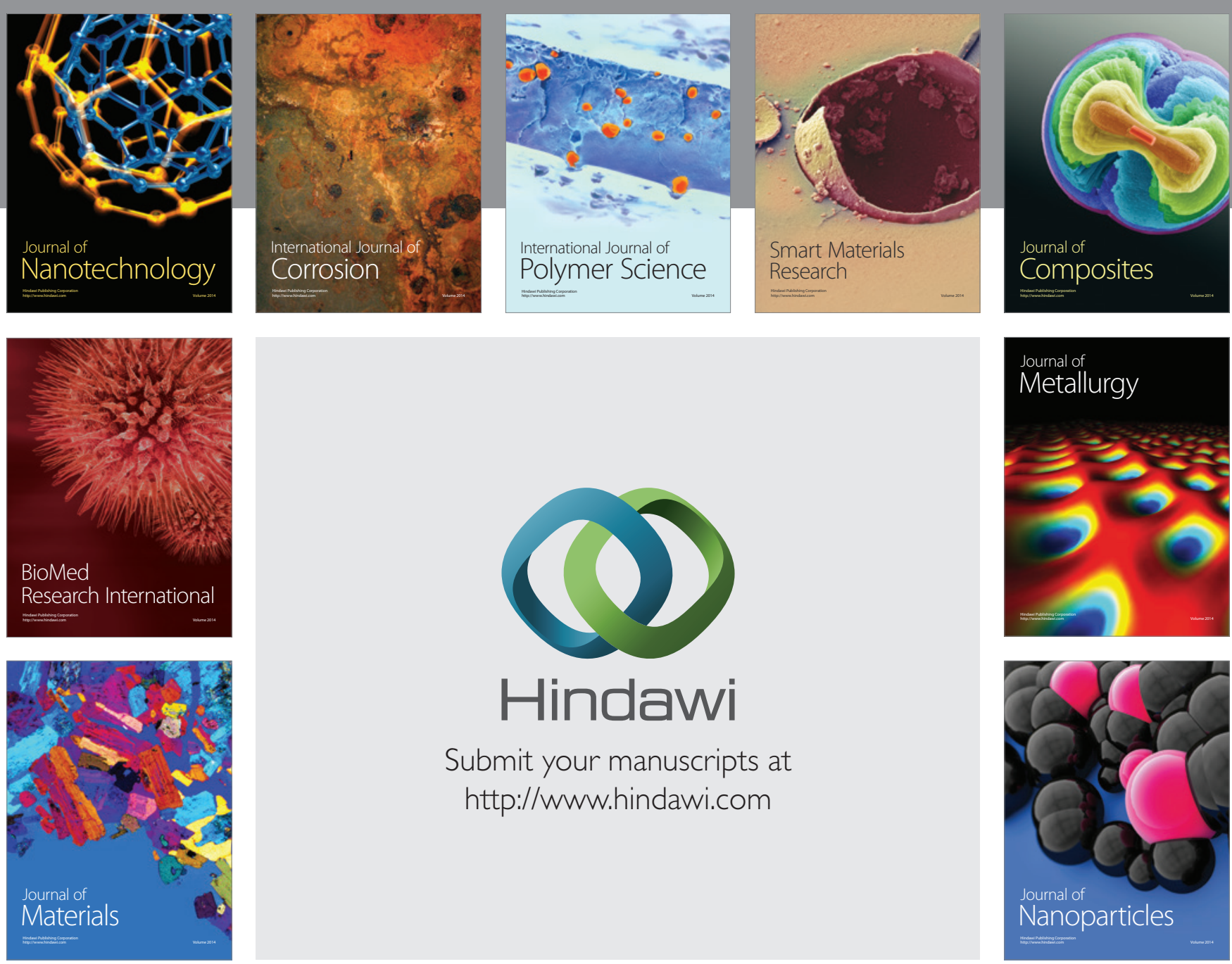

Submit your manuscripts at http://www.hindawi.com
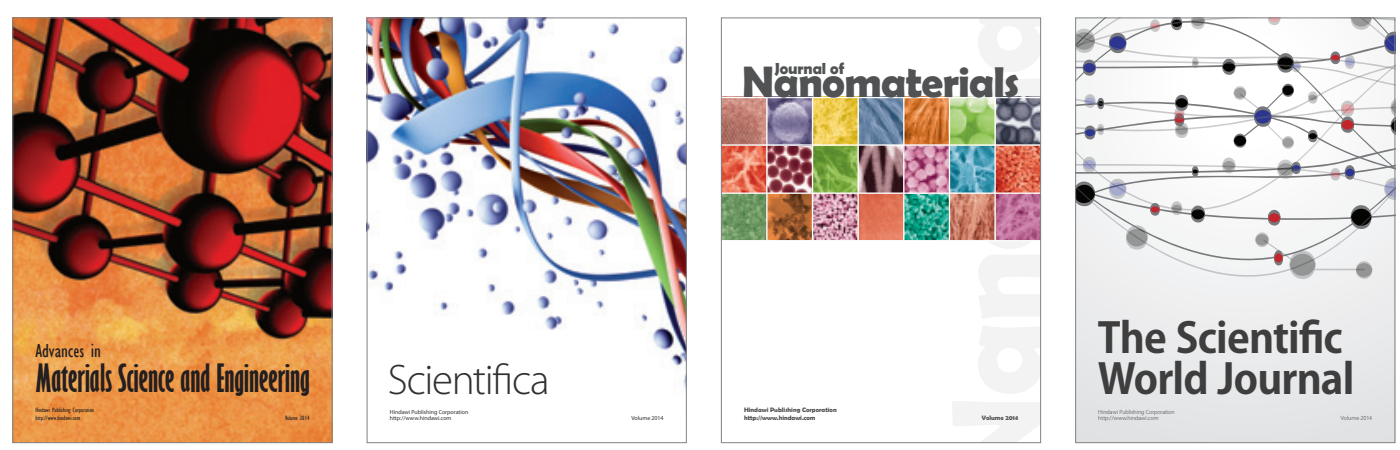

\section{The Scientific World Journal}
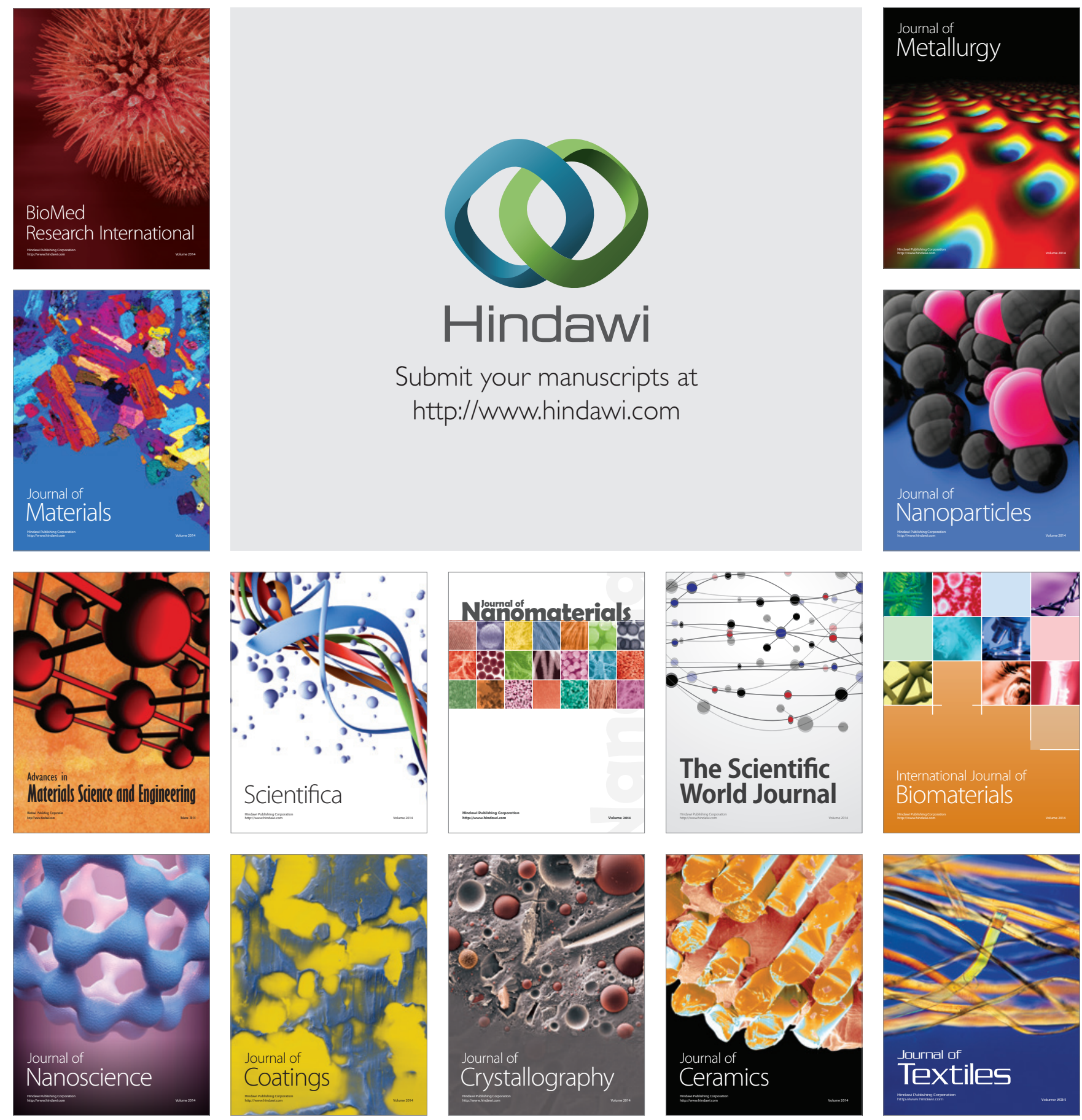